\title{
Pemberdayaan petani aren (Arenga pinnata Merr) rakyat melalui diversifikasi produk nira aren di Desa Mabar Kecamatan Bangun Purba Kabupaten Deli Serdang
}

\author{
Sri Wahyuni* \\ Universitas Muslim Nusantara Al Washliyah Medan \\ *wsri00141@gmail.com
}

\begin{abstract}
Abstrak. Nira aren sangat berpotensi untuk dijadikan gula karena nira tersebut mengandung komponen gula yang dominan yaitu jenis sukrosa. Gula Aren asal Desa Mabar Kecamatan Bangun Purba dikenal sebagai gula aren yang benar-benar murni. Masalah yang dihadapi para petani aren di desa ini adalah belum terlihatnya usaha gula aren ini menjadi usaha yang dapat diandalkan untuk meningkatkan ekonomi keluarga. Tujuan kegiatan pengabdian masyarakat ini adalah untuk memfasilitasi para petani aren supaya dapat meningkatkan usaha mereka dan dapat menjadi usaha yang produktif. Metode yang dipakai dalam kegiatan ini adalah penyuluhan/edukasi, implementasi teknologi dari tim Pengabdian Kepada Masyarakat. Hasil yang dicapai dalam kegiatan ini mitra yaitu petani aren diberikan sosialisasi cara pengolahan, implementasi alat dari tradisional menjadi modern. Hasil luaran yang dicapai adalah sirup gula aren dan gula semut.
\end{abstract}

Kata kunci: sirup gula aren; gula semut; diversifikasi

\begin{abstract}
Palm sap has the potential to be used as sugar because it contains the dominant sugar component, the type of sucrose. Palm Sugar from Mabar Village, Bangun Purba District is known as truly pure palm sugar. The problem faced by palm farmers in this village is that the palm sugar business has not yet become a reliable business to improve the family economy. The purpose of this community service activity is to facilitate the sugar palm farmers so they can improve their businesses and become productive businesses. The method used in this activity is counseling / education, technology implementation from the Community Service Team. The results achieved in this activity partners namely sugar palm farmers are given a way of socializing processing, implementation of tools from traditional to modern. The results achieved are palm sugar syrup and palm sugar.
\end{abstract}

Keywords: palm sugar syrup; ant sugar; diversification

To cite this article: Wahyuni, S. 2019. Pemberdayaan petani aren (Arenga pinnata Merr) rakyat melalui diversifikasi produk nira aren di Desa Mabar Kecamatan Bangun Purba Kabupaten Deli Serdang. Unri Conference Series: Community Engagement 1: 104-107. https://doi.org/10.31258/unricsce.1.104-107

(C) 2019 Author

Peer-review under responsibility of the organizing committee of Seminar Nasional Pemberdayaan Masyarakat 2019 


\section{PENDAHULUAN}

Gula Aren atau biasa disebut dengan gula merah. Di pasar global gula aren dikenal sebagai brown-sugar, tetapi ada juga yang menyebut palm sugar. Gula aren dihasilkan dari nira pohon enau dengan pengolahan yang masih terbilang tradisional. Nira dari pohon enau disadap dari pujuk/tangkai buah. Gula aren sudah dikenal sejak lama oleh masyarakat Indonesia, terutama penduduk pedesaan yang masih menggunakan gula aren sebagai gula konsumi sehari-hari disbanding dengan gula tebu (Lalisang, 2018)

Gula aren tidak hanya dapat dimanfaatkan sebagai gula pada umumnya yang dicampur dalam jenis makanan atau minuman atau panganan tertentu. Di samping penggunaannya, gula aren memiliki manfaat yang cukup banyak dalam bidang kesehatan, seperti : Meningkatkan sistem imunitas tubuh; Gula aren aman bagi penderita diabetes; dan lain-lain (Joseph \& Layuk, 2012)

Kebutuhan gula sebagai bahan pemanis di Indonesia semakin lama semakin meningkat, impor gula pada tahun 2003 sebesar 1,55 juta ton dan pada tahun 2007 meningkat tajam 108 persen menjadi 2,6 juta ton . Melihat kenyataan tersebut, upaya yang dapat dilakukan oleh Pemerintah dalam jangka dekat adalah produksi gula non-tebu. Oleh sebab itu alternatif yang paling memungkinkan untuk memproduksi gula yang melibatkan industri kecil adalah industri gula palma (Radam \& Agustina, 2015).

Desa Mabar Kecamatan Bangun Purba merupakan daerah yang memiliki lahan perkebunan aren yang cukup luas, sehingga daerah ini mempunyai peluang investasi yang besar dalam lingkup penghasil nira aren. Selama ini, masyarakat Desa Mabar hanya mengambil aren sebagai hasil dari perkebunan aren dan mengolahnya secara tradisional menjadi gula cetak dan alat yang digunakan masih sangat sederhana. Kegiatan pengolahan gula cetak di desa mabar menurut mereka belum dapat menjadi usaha andalan untuk meningkatkan perekonomian keluarga dan selain gula cetak, nira yang mereka ambil agar hasilnya menguntungkan biasanya mereka langsung menjualnya ke perusahaan kue atau agen pembuat tuak walaupun harganya rendah. Oleh sebab permasalahan tersebut para petani dan pengrajin gula merah tidak selalu memproduksinya setiap hari. Permasalahan yang lain juga para petani juga belum dapat mengembangkan profesi mereka dan belum mampu berkreasi untuk mengembangkan profesi mereka dengan cara memberi nilai tambah, sehingga usaha yang digeluti semakin menguntungkan. Dari hasil permasalahan pihak petani/pengrajin kegiatan Pengabdian Kepada Masyarakat ini bertujuan untuk meningkatkan nilai tambah pada petani/pengrajin aren untuk dapat berkreasi membuat produk selain gula cetak yaitu dalam bentuk diversifikasi produk lain yaitu sirup gula aren dan gula semut agar meningkatkan nilai tambah dari aren tersebut.

\section{METODE PENERAPAN}

Berdasarkan permasalahan mitra, adapun untuk mencapai tujuan yang akan dicapai maka:

\section{Tahap persiapan}

Persiapan yang dilakukan adalah melakukan sosialisasi dan penyuluhan

a. Sosialisasi. Metode ini digunakan untuk memberikan wawasan tentang kewirausahaan dan meningkatkan pemahaman pengetahuan dan ketrampilan dalam hal diversifikasi produk, sehingga dapat meningkatkan nilai tambah. Metode ini digunakan untuk meningkatkan pengetahuan mitra tentang manajemen usaha.

b. Penyuluhan/Edukasi. Metode ini digunakan untuk melihat pemahaman dan ketrampilan tentang upaya meningkatkan nilai tambah air nira menjadi sirup gula aren dan gula semut.

\section{Tahap Pendampingan}

Metode pendampingan meliputi pengolahan dan pengawasan yang digunakan untuk melihat peserta sejauh mana memahami penjelasan dari materi yang di uraikan untuk pembuatan sirup gula aren dan gula semut. 


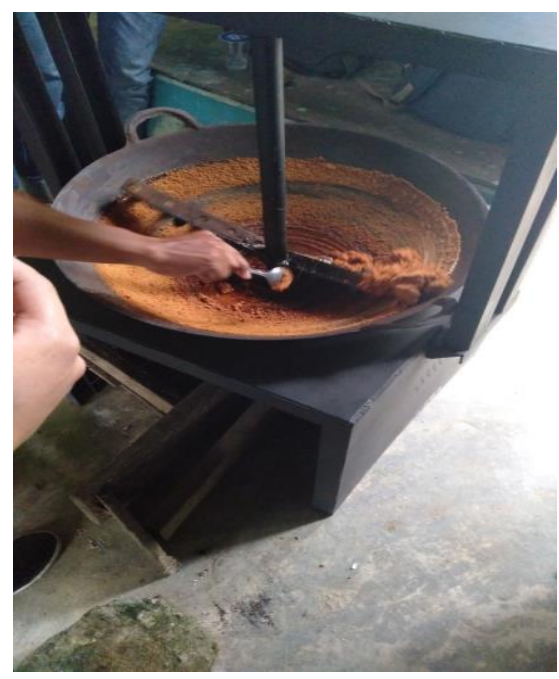

Gambar 1. Pembuatan Gula Semut

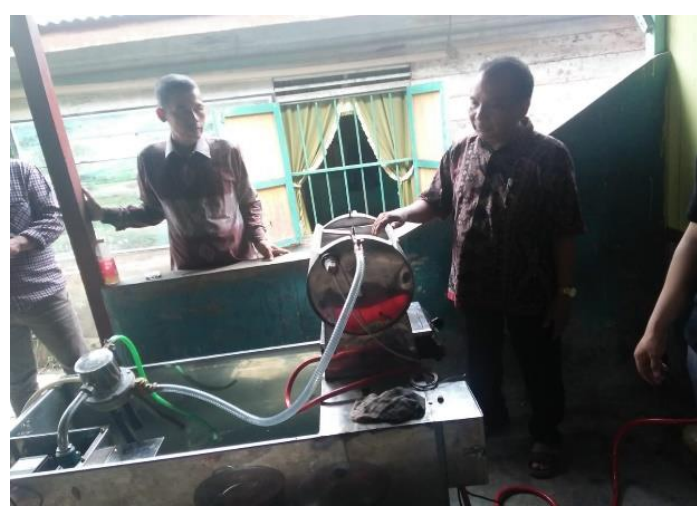

Gambar 2. Pembuatan Gula Cair

\section{HASIL DAN KETERCAPAIAN SASARAN}

Peningkatan Pengetahuan Tentang Pengolahan Produk Diversivikasi aren di Desa Mabar Kecamatan Bangun Purba Kabupaten Deli Serdang.

Hasil yang telah dicapai dalam kegiatan Pengabdian kepada Masyarakat ini berupa peningkatan pengetahuan tentang nilai tambah suatu produk. Petani aren/Pengrajin memahami tentang proses merubah bahan baku menjadi barang jadi. Sebelum diadakan kegiatan pengabdian ini, petani aren hanya mengolah nira aren masih secara tradisional yaitu dalam bentuk gula cetak dengan menggunakan peralatan yang tradisional. Setelah kegiatan Pengabdian Kepada Masyarakat ini hasil luaran produk yaitu sirup gula aren dan gula semut yang telah dikemas.

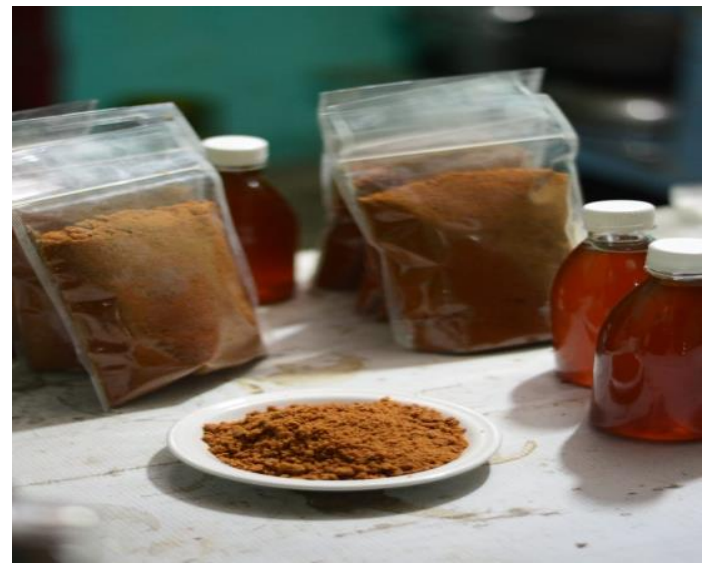

Gambar 3. Produk Gula Semut dan Gula semut 


\section{Tingkat Pendapatan}

Sebelum dilaksanakan kegiatan Pengabdian Kepada Masyarakat, para petani/pengrajin gula aren hanya menjual sebatas gula cetak dengan harga per kg nya yaitu Rp.20.000, sedangkan di pasar harganya sekitar Rp.13.000/kg jauh lebih murah, padahal mutu dari aren yang dipasar kebanyakan gulanya dioplos yaitu bukan gula aren murni akan tetapi dicampur dengan bahan yang lain untuk di pasarkan ke konsumen. Untuk nira aren mentah terkadang masih dijual mereka pada pengusaha kue dan pengusaha tuak dengan harga jauh lebih rendah yaitu Rp.3000/liter nya. Oleh sebab itu kegiatan ini tidak dapat diandalkan untuk perekonomian keluarga. Dalam pelaksanaan kegiatan ini, masalah yang dihadapi petani aren tersebut dapat diatasi dengan cara membuat produk lain melalui program diversifikasi membuat gula cair aren dan gula semut, selain itu Solusi dari kendala yang dihadapi yaitu mencari pemasaran yang tepat dan alternatif untuk memasarkan produk ini langsung ke konsumn untuk mencegah terjadinya produk tiruan sehingga dapat layak dikonsumsi oleh masyarakat secara aman. Selain itu, kegiatan pengolahan produk diversifikasi menjadi gula semut yang harganya jauh lebih tinggi yaitu Rp. 50.000- 60.000 per kg, dan gula aren cair harganya sekitar Rp.25.000 per botolnya, dari pengolahan diversifikasi ini cukup significant dapat menambah pendapatan petani aren dan layak untuk dikonsumsi oleh konsumen.

\section{KESIMPULAN}

Hasil kegiatan Pengabdian masyarakat ini dapat disimpulkan sebagai berikut :

1. Terdapat perubahan pola pikir petani kearah pengembangan usaha diversifikasi olahan tanaman aren menjadi gula cair dan gula semut.

2. Peningkatan pemahaman tentang produk olahan dari gula tradisional menjadi olahan produk diversifikasi sehingga akan menambah nilai suatu produk

3. Meningkatkan Pendapatan petani aren, selain dari gula cetak melalui kegiatan diversifikasi ini.

\section{UCAPAN TERIMA KASIH}

Penghargaan dan ucapan terimakasih penulis sampaikan kepada pihak Direktorat Riset dan Pengembangan Dirjen Pendidikan Tinggi Kementerian Ristek dan Pendidikan Tinggi Republik Indonesia, yang telah memberikan dukungan dana sehingga kegiatan Pengabdian Masyarakat dapat dilaksanakan.

\section{DAFTAR PUSTAKA}

Joseph, G. H., \& P. Layuk. 2012. Pengolahan Gula Semut dari Aren. Litbang Pertanian 13(1): 60-65. jurnal.litbang.pertanian.go.id/index.php/palma/article/download/5596/4771\%0A\%0A

Lalisang, I. 2018. Pemberdayaan Petani Aren melalui Diversivikasi Produk Olahan Air Nira. Jurnal Pengabdian Kepada Masyarakat 23(4): 415. https://doi.org/10.24114/jpkm.v23i4.8938

Raliby, O. 2015. Inovasi Teknologi melalui Diversifikasi Produk Gula Kelapa Industri Rumahan Menuju Usaha Kecil Dinamis (Small Dynamic Enterprise). Seminar Nasional IENACO - 2015, 541-548. Retrieved from https://publikasiilmiah.ums.ac.id/handle/11617/5910?show=full

Radam, R. R., \& R. A. Agustina. 2015. Pengolahan Gula Aren (Arrenga Pinnata Merr) di Desa Banua Hanyar Kabupaten Hulu Sungai Tengah. Jurnal Hujan Tropis 3(3): 267-276. Retrieved from https://docplayer.info/47879976-Pengolahan-gula-aren-arrenga-pinnata-merr-di-desa-banua-hanyar-kabupatenhulu-sungai-tengah.html 